\title{
Research on Network Platform of Agricultural IOT Technology Based on WeChat
}

\author{
Cuihua Sun ${ }^{1, a}$, Yong Ge $e^{2, b}$, Liang Xue ${ }^{1, c}$ and Qianghe Qun ${ }^{1, d}$ \\ ${ }^{1}$ Smart Agriculture collage, Suzhou Polytechnic Institute of Agriculture, Suzhou 215008, China \\ ${ }^{2}$ Suzhou Power Supply Company, Suzhou 215004, China \\ a39938737@qq.com, b373878049@qq.com, 61230375 @qq.com, d32560475@qq.com
}

\section{Keywords: Network platform; WeChat; micro curriculum; Agricultural IOT; IOT technology}

\begin{abstract}
This paper analyzes the overall structure of curriculum resources platform, to "agricultural IOT technology" course as an example, the design of each function module of the platform, the platform of WeChat communication mechanism, and gives the main code. And Experiments show that the platform has good early warning performance.
\end{abstract}

\section{Introduction}

WeChat is a free application that provides instant messaging services for smart terminals in January 21, 2011, launched by Tencent Inc, and led by Xiaolong Zhang, Tencent Guangzhou R \& D center product team [2]. WeChat supports cross communication operators, cross operating system platform through the network quickly send free voice messages, video, pictures and text, in less than three years WeChat has become the hottest social information platform, in 26 countries and regions App Store rankings ranked first[3-4].

Agricultural IOT technology is through a number of information collection, transmission, control and other equipment together, constitute a monitoring network, on agricultural production environment of soil, fertilizer, air temperature and humidity information acquisition and analysis network technology to achieve automation, intelligent and remote control. With the application of Internet of things technology in traditional agriculture, precise controls of agricultural production have made traditional agriculture more intelligent [5].

From the angle of WeChat technology analysis and WeChat mobile learning platform construction, this paper takes "Agricultural IOT technology" course as an example, and constructs a convenient and lightweight computer mobile learning platform.

\section{Platform Architecture}

The network platform has two modules, the onstage user operation and the backstage management, and the onstage is divided into six big function modules, and the backstage is composed of seven parts.

Front Function Module of the Platform. "Agricultural IOT technology" curriculum cyber source platform foreground main function module is composed of six parts, divided into the information system management, teaching area, download, communication and discussion area, exhibition area and area of effect evaluation. System management module contains seven functions, namely class management, professional management, document type management, school guidance, teacher management, enterprise guidance, teacher management, student management and student score management. Module teaching guidance area contains four functions, which are asynchronous video and synchronous video, operating release and operation check "data download module includes four functions, namely teaching courseware, teaching files, file management and students' self-study materials. Communication forum module contains two functions, respectively. Is to discuss the setting and discussion of" exhibition area "contains four function modules, respectively is the student works show, students show, teachers show and studio exhibition, the evaluation module contains three functions, namely, setting time and I see all the evaluation platform the 
function module as shown in the Fig. 1.

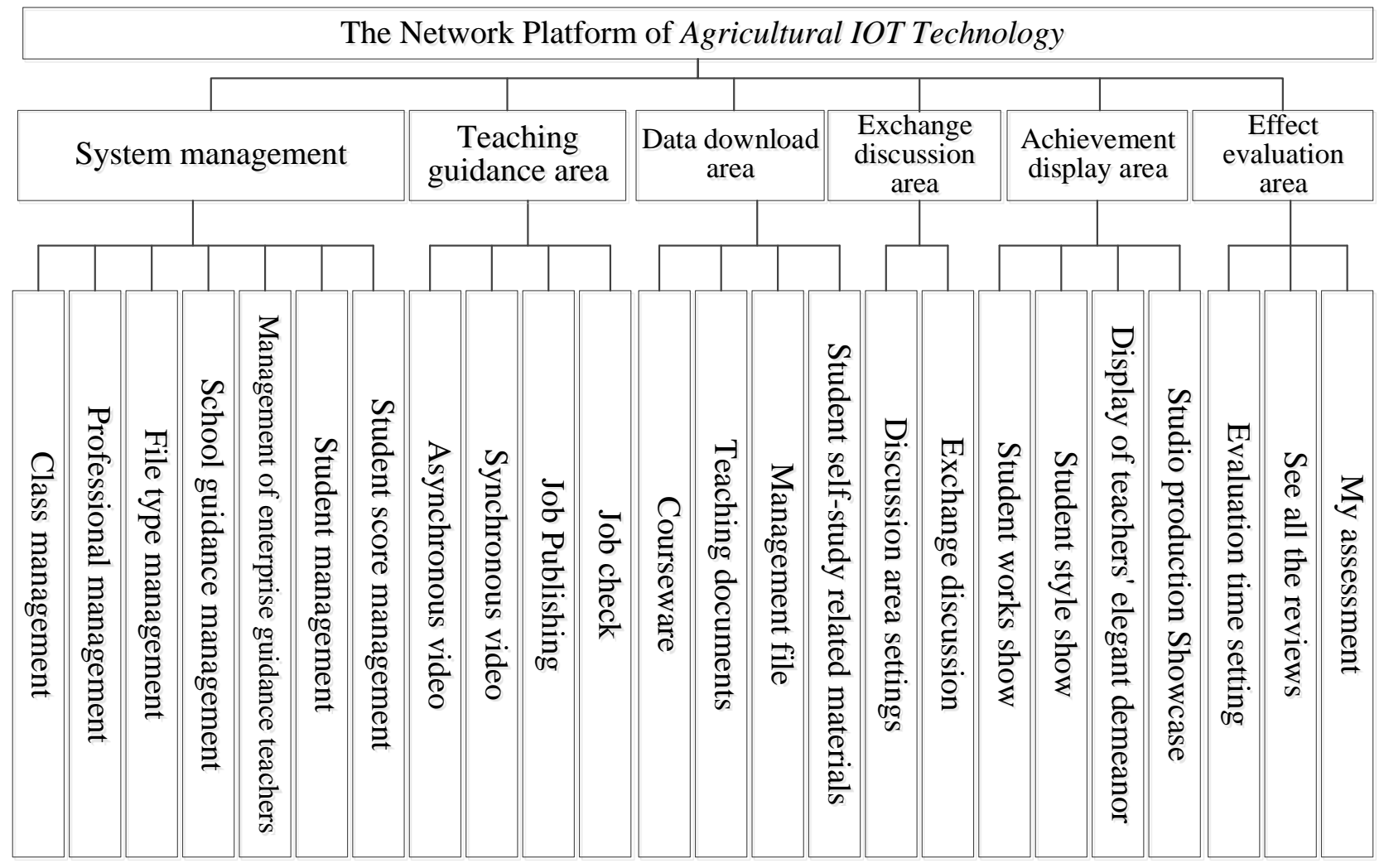

Figure 1. Finite Function module diagram of the platform

Backstage Function Module of the Platform. The main function module of the network resource platform of "Agricultural IOT technology" is composed of seven parts. They are divided into group function, automatic reply, voting management, user management, material management and statistical module as shown in the Fig. 2.

\section{The Key Technology}

WeChat's Communication Mechanism. The request interface layer is used to process the HTTP request and response. The distribution layer is passed in by the interface layer and then specifically analyzed by request type and distributed to different processors. Business logic layer is our specific business logic, according to the request, to achieve specific business logic. When you implement an application, a data layer may need to access data, either a database or a data file. In fact, the specific application can be extended in this structure, which can extend the message object layer, business object layer, data access layer, function management layer and so on[6-8]. The WeChat communication flow chart is shown in the Fig. 3.

WeChat Library. The WeChat end library handles three function modules: information about events, push, custom menus, event push, and text messages [9].

Attention: in the event processing push users started to focus on the public number, programmed to get WeChat documents, so as to extract the user's WeChat nickname information; call My SQL string processing functions to update the database, new or updated data in the corresponding table. Processing custom menu events push: when the user clicks on the menu, the click event pushed to developers, through the programming to the content of message from XML format to structure form, and the system only to judge the converted event value can respond; when the user clicks on the menu jump links, direct jump start ", performed by WeChat to end. Dealing with text messages: through simple selection, control branch statements, determine specific text message strings, and perform specific functions. 


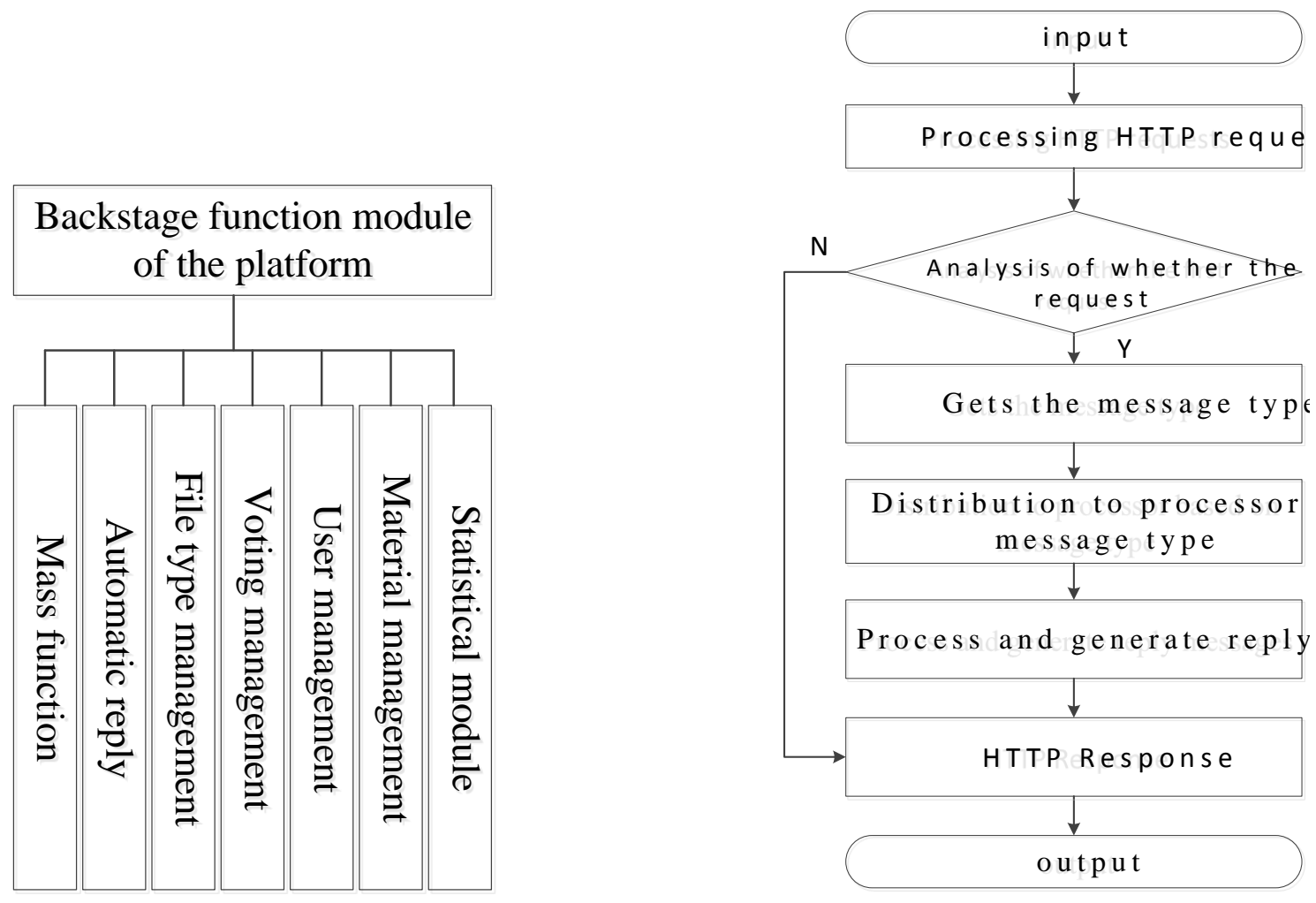

Figure 2. Finite Backstage function module

Figure 3. Finite WeChat's communication mechanism

Main code. The following sections analyze the three parts of the main code, including twodimensional code, two-dimensional code scanned, and successful login.

(void)onAuthGotQrcode:(UIImage *)image

\{NSLog(@"onAuthGotQrcode"); \}

(void)onQrcodeScanned

\{NSLog(@"onQrcodeScanned"); \}

(void)onAuthFinish:(int)errCode AuthCode:(NSString *)authCode

\{NSLog(@"onAuthFinish");

UIAlertView*alert=[[UIAlertView alloc]initWithTitle:@ "onAuthFinish" message: [NSString string WithFormat : @ "authCode:\%@ errCode:\%d", authCode, errCode] delegate:self cancelButton Title :@"OK" otherButtonTitles : nil, nil];

[alert show]; \}

\section{Simulation experiment}

The input signal of micro or two-dimensional code scanning directly concern the public "agricultural IOT technology", the main page into the WeChat platform, according to clew, send "start learning", "new information" and "other operations" can enter the corresponding module. Send "start learning", enter "Agricultural Internet of things technology" curriculum module, reply $1 \sim 10$, enter the corresponding sub modules respectively. Send the number 1 into the program preview, click push information to view the next class syllabus, the difficulty in the outline of the logo, can make students more targeted to achieve better preview, preview effect.

\section{Conclusions}

In order to change the traditional teaching mode of teaching problems, this paper takes "agricultural IOT technology" course as an example, studies the course platform based on WeChat's cyber source, the mobile device as the carrier, so that learners can use their spare time in any place at any time in a short period of time to complete the study, meet the personalized learning needs. After testing, the platform functions can be used normally, meet the design requirements. 


\section{Acknowledgements}

This work was sponsored by Qing Lan Project, supported by the education "13th Five-Year" Planning issues of Jiangsu province (B-b/2016/03/41), the modern educational technology research project of Jiangsu province (2017-R-58821), and depth integration training platform of production and education of Jiangsu Province on 2016 (The depth integration training platform of intelligent digital plant factory production of production and education).

\section{References}

[1] Information on http://www.chinastor.org/GuoNeiXinWen/8699.html

[2] Information on http://tech.163.com/14/0228/14/9M67OQ9100094ODU.html.

[3] Y. Zhou: Computer Knowledge and Technology, Vol. 10 (2014) No.32, p.7605 (In Chinese).

[4] Information on http://weike.enetedu.com/report

[5] L. Zhang, W. W. Ma and Y. J. Cao: journal of Anshan University, Vol. 18 (2016) No.4, p.45 (In Chinese).

[6] B. Sun: Electronic Design Engineering, Vol. 25 (2017) No.10, p.48 (In Chinese).

[7] Information on http://mp.weixin.qq.com/cgi-bin/loginpage?t=wxm2-login\&lang=zh_CN

[8] Information on http://open.weixin.qq.com/cgi-bin/index?t=home/index\&lang=zh_CN

[9] J. S. Xu, Y. H. Zhen, Y. B. Chen, Y .F. Chen and T. Ye: Internet Technology, Vol. 10 (2017) No.11, p.73 (In Chinese). 